\title{
Decision Support Systems (DSS): A survey
}

\author{
H.W. Ittmann \\ National Research Institute for Mathematical Sciences, Council for Scientific and Industrial Research, Pretoria
}

\begin{abstract}
Interest in aiding and supporting decision-making through the use of computers has been stimulated by technological developments in areas such as personal computers, computer networks, large data bases, colour graphics and computer-based models. These uses are known as Decision Support Systems (DSS) and imply computer systems designed to extend managers' capabilities, and at the same time to integrate these uses into existing managerial activities and needs. During the past few years there have been rapid international developments in the DSS field. In South Africa this trend is also noticeable, although on a smaller scale. The object of this article is to give a survey of Decision Support Systems by defining the concept and by showing how it relates to other fields, and to present a framework of the typical functions and components of such a system. Some practical applications are discussed for illustrative purposes.
\end{abstract}

S. Afr. J. Bus. Mgmt. 1984, 15: 189-196

Die gebruik van rekenaars as hulpmiddels en as ondersteuning vir besluitneming is tot ' $n$ groot mate gestimuleer deur tegnologiese ontwikkeling op die gebied van rekenaars en meer spesifiek persoonlike rekenaars, rekenaarnetwerke, groot databasisse, kleurgrafieke en rekenaargebaseerde modelle Hierdie gebruike staan bekend as besluitnemingondersteuningstelsels en impliseer rekenaarstelsels wat ontwerp is om bestuurders se vermoëns uit te brei, terwyl dit terselfdertyd deel word van bestuur se huidige aktiwiteite en behoeftes. Oor die afgelope paar jaar was daar internasionaal heelwat ontwikkelinge op hierdie gebied. Dié neiging is ook in Suid-Afrika waarneembaar, hoewel op 'n kleiner skaal. Die doel van hierdie artikel is om ' $n$ oorsig te gee van besluitnemingondersteuningstelsels deur die konsep te definieer en die verwantskap daarvan met ander velde aan te toon, asook om 'n raamwerk daar te stel van die funksies en komponente van so 'n stelsel. 'n Paar praktiese toepassings word bespreek vir toeligtingsdoeleindes. S.Afr. Tydskr. Bedryfsl. 1984, 15: 189-196

\section{Introduction}

The phenomenal and rapid technological developments in the computer industry have stimulated the use of computers to support decision-making at all levels of management. These uses are designated by the term Decision Support Systems (DSS). Such systems not only make practical use of the latest developments in computer technology and management information systems (MIS), enabling their synthesis, but, possibly more important, also allow for the incorporation and use of more quantitative models, such as simulation and optimization. Remarks on these systems have ranged from 'a major breakthrough' to 'just another buzz word'. Some critics view the current thrust in DSS as the natural advancement or continuation of the development from electronic data processing (EDP) to MIS. Others, such as Naylor, regard DSS as just a name for certain types of systems and models that have been developed over a number of years (Naylor, 1982:92-94). This survey tries to place the notion of DSS in perspective according to definition, functions, components, etc., as used in the current literature.

In 1978 Ackoff delivered two, now quite famous, papers at the Annual Conference of the Operational Research (OR) Society of the United Kingdom which shocked the entire international OR community (Ackoff, 1979a:93 - 104; 1979b: 189-199). In the first, entitled 'The Future of Operational Research is Past', Ackoff states that as far as he is concerned $\mathrm{OR}$, as originally conceived, is dead. He discusses various changes in the environment of OR which should have evoked adaptation, but which did not. One of these is the need for decision-making systems that can learn and adapt quickly to changes. To motivate this he states:

'The structure and the parameters of problematic situations continuously change, particularly in turbulent environments. Because optimal solutions are very seldom made adaptive to such changes, their optimality is generally of short duration. They frequently become less effective than were the often more robust solutions that they replace. Let us call this cross-over point the moment of death of this solution. . . . the life of solutions to many critical social and organizational problems is shorter than the time required to find them. Therefore, more and more so-called optimal solutions are still-born. With the accelerating rate of technological and social change ... the expected life of optimal solutions and the problems to which they apply can be expected to become increasingly negative. For these reasons there is a greater need for 
decision-making systems that can learn and adapt quickly and effectively in rapidly changing situations than there is for systems that produce optimal solutions that deteriorate with change. Most Operational Researchers have failed to respond to this need. As a consequence, the application of $O R$ is increasingly restricted to those problems that are relatively insensitive to their environments'

In the year in which Ackoff spoke these words, the first book on DSS by Keen \& Scott Morton was published (Keen \& Scott Morton, 1978). Since then further books on this topic, and a number of articles, both research and applicationsoriented, have been published. From these it is clear that a DSS addresses the specific aspect identified by Ackoff as one of the serious deficiencies within OR.

\section{DSS: Definitions}

In giving an overview of DSS it is important to establish the meaning of the term. Various interpretations of 'DSS' have been given and some of these are described below.

The concept of DSS was first defined by Michael S. Scott Morton as 'management decision systems' in the early seventies (Scott Morton, 1977). More and more people began to work in the field of DSS which became characterized as 'interactive computer based systems which help decision-makers utilize data and models to solve unstructured problems' (Sprague, 1980a:1-26).

Keen \& Scott Morton give the following view: 'DSS represents a point of view on the role of the computer in the management decision-making process (Keen \& Scott Morton, 1978). Decision support implies the use of computers to:

(i) Assist managers in their decision process in semistructured tasks.

(ii) Support, rather than replace, managerial judgement.

(iii) Improve the effectiveness of decision-making rather than its efficiency'.

Another general description is given by Wagner: 'A particular system is considered a DSS to the extent that it provides interactive support for the thought processes of one or more executives in their principal function of making decisions' (Wagner, 1981:77-86).

Keen \& Wagner describe a DSS as a computer-based system which is used personally on an ongoing basis by managers and their immediate staff in direct support of managerial activities, that is, decision-making (Keen \& Wagner, 1979:117-122). According to them, another term for a DSS might be: 'executive mind-support system'.

Bonczek, Holsapple \& Whinston take the view that DSS may be considered as merely a renaming of MIS as a result of the following differences between the two approaches (Bonczek, Holsapple \& Whinston, 1981).

(i) A DSS incorporates models into the information systems software;

(ii) a DSS provides useful information to management to support comparatively unstructured decision activities; and

(iii) a DSS provides a simple-to-use language for problem solving.

They refer to the information-processing system that is embedded within a decision-making system as a DSS. Such a system utilizes ideas and techniques from the areas of management sciences, data-base management, formal logic, linguistics and artificial intelligence. The three distinctions which Bonczek, Holsapple \& Whinston make between MIS and DSS, coincide to a large extent with the views of other writers.

A better understanding of a DSS and its potential can be obtained by looking at its capabilities in terms of specific and observed characteristics. At a conference on DSS four characteristics of a DSS were highlighted:

(i) A DSS facilitates interaction between computers and decision-makers. For example, a DSS is 'an effort to bring the computer closer to the decision-maker'.

(ii) A DSS assists managers in making unstructured or partially structured decisions in which judgemental issues are paramount. For example, a DSS 'allows a decisionmaker to ask ad hoc questions in a non-procedure English-like query language'.

(iii) A DSS is comprehensive with regard to the types of decision processes supported and functions it can perform.

(iv) A DSS is useful, meaning that it applies to the subset of management information systems that truly support decision-making processes' (Carlson, 1977).

Sprague summarizes the characteristics of a DSS as follows:

(i) 'It tends to be aimed at the less well-structured, underspecified problems that upper level managers typically face.

(ii) It attempts to combine the use of models or analytic techniques with traditional data access and retrieval functions.

(iii) It specifically focuses on features which make it easy to use by non-computer people in an interactive mode.

(iv) It emphasizes flexibility and adaptability to accommodate changes in the environment and the decisionmaking approach of the user' (Sprague, 1980a:1-26).

He further stresses that a DSS is regarded by an organization as being at a higher level than EDP and MIS, with emphasis on:

(a) Being decision-focused and aimed at top managers and executive decision-makers;

(b) having flexibility, adaptability and quick response;

(c) being user-initiated and controlled; and

(d) supporting the personal decision-making styles of individual managers.

From the above one can extract and state the key components and characteristics of a typical DSS as follows:

(i) It is computer based;

(ii) it aids decision-makers in solving semi-structured and unstructured problems;

(iii) it plays a supportive role in the decision-making process and does not automate or replace this process;

(iv) it generates information via models in support of decisions;

(v) it is highly adaptable and flexible in a dynamic environment;

(vi) it is easy to use and operates in an interactive mode.

\section{Distinctions between DSS and MIS and OR/MS}

Although, as is perhaps evident from the previous section, many feel that the concept of DSS overlaps the areas of MIS and Operations Research/Management Science (OR/MS), it does differ in terms of its impact and benefit to organizations and its relevance to managers. Many writers also differ on whether DSS is a new tool, whether it is a new approach parallel to MIS and OR/MS or whether it subsumes them. Before giving a verdict on this issue, the differences between these concepts, as seen by soine authors, are given.

Keen \& Scott Morton (1978) make the following distinctions: 


\section{MIS}

- The main impact has been on structured tasks in which operating procedures, decision rules and information flows can be predefined;

- the main benefit has been in improving efficiency by reducing costs, turn-around time, etc., by replacing clerical personnel; and

- the relevance for managers' decision-making has been mainly indirect i.e., by providing reports and access to data.

\section{Traditional OR/MS tools}

- The impact has been on structured problems where the objectives, data, and constraints can be pre-specified;

- the benefit has been in generating better solutions for given types of problems; and

- the relevance for managers has been the provision of detailed recommendations and new methodologies for handling complex problems.

\section{DSS}

- The impact is on decisions in which there is sufficient structure for computer and analytical aids to be of value but in which managers' judgement is essential;

- the benefit is in extending the range and capability of managers' decision processes to help them improve their effectiveness; and

- the relevance for managers is the creation of a supportive tool, under their own control, which does not attempt to automate the decision process, predefine objectives, or impose solutions.

To many, the OR/MS process is characterized by formal mathematical optimization methods. Vazsonyi, however, in comparing OR/MS with the DSS notion, expresses the view that optimization is an important but not indispensable aspect of OR/MS (Vazsonyi, 1978:72-77). He identifies other aspects of the OR/MS process by dividing it into four stages, namely:

(i) Exploration - the phase in which the initial structuring of the situation is accomplished.

(ii) Modelling and optimization.

(iii) Interpretation of post-modelling - here the results of the model are translated into plain English and communicated to the decision-maker.

(iv) Implementation.

Modelling and optimization have received much attention in the OR/MS literature and great progress has been made in these areas during the last decade, but the same does not apply to the other aspects mentioned. Vazsonyi, however, claims that 'DSS can provide the technology to support the process of (a) exploring/structuring, (b) interpreting, and (c) implementing' (Vazsonyi, 1978).

In addition, 'DSS technology provides the capability of storing, retrieving, presenting and manipulating data in an online, real-time fashion; it provides the capability of manmachine dialogue; and it can provide online, real-time capability of structuring a situation and building a model' (Vazsonyi, 1978).

Sprague \& Carlson give a concise summary of the distinction between a DSS and other technology 'subsystems', such as EDP, MIS, office automation (OA), and word processing (WP), which provide support for the activities of managers and other workers (Sprague \& Carlson, 1982). Whereas EDP and MIS support the information-reporting needs of the organization, both internally and externally, and OA and WP the communications needs, a DSS supports the decisionmaking functions. 'DSS seems to be evolving from the coalescence of information technology and OR/MS approaches in the form of interactive modelling' (Sprague \& Carlson, 1982). A DSS is not merely an evolutionary extension of EDP and MIS and will not replace either. It is rather 'a class of information systems that draws on transaction processing systems and interacts with the other parts of the overall information system to support decision-making activities' (Sprague \& Carlson, 1982).

The DSS movement addresses, specifically, decisionmaking problems of a semi-structured or unstructured nature, that is, problems which have had little or no support from either MIS or OR/MS in the past. Whereas MIS is more concerned with data handling, information flow, inquiry, report generation, etc, a DSS is decision-focused, although it could make use of data provided by MIS. There will always be a need for MIS or the type of functions it provides and therefore it will not be replaced by DSS.

The traditional OR/MS approach has been to solve structured problems and to provide 'optimal' or better solutions which do not require managerial judgement. A DSS differs from this traditional view of OR/MS in that it does not try to impose a solution on the decision-maker. It is rather a supportive tool in all phases of decision-making, aimed at improving the effectiveness of decision-making. DSS should be seen as something which falls naturally within the scope of OR/MS. It does not, however, replace traditional OR/MS techniques, for which there will always be a need; neither should DSS be seen simply as a new tool of OR/MS, but rather as a new concept which broadens the scope and capabilities of the OR/MS practitioner. DSS is a new approach, owing mainly to the rapid technological developments in the computer industry, to solve less well-structured problems and should be used parallel to traditional OR/MS and MIS.

\section{Semi-structured problems}

In defining a semi-structured problem, we first need to look at the definition of structured and unstructured tasks. A structured problem is one for which the solution process can be fully automated and which thereafter does not require any managerial intervention. An unstructured problem, on the other hand, is one which cannot be automated in this way, and has to be solved through intuitive reasoning by managers. Semi-structured problems lie between these two extremes. Here one can identify areas of the decision process which can be structured and can therefore be automated, as well as areas which are judgemental or unstructured and must be left to the decision-maker. There is a 'best' way to solve the structured areas, while the other tasks require each manager to make personal situational value judgements.

Criteria for the development of a DSS are very different from the requirements for structured situations. Keywords are learning, interaction, support, and evolution, rather than replacement, solution procedures, and automation.

\section{Effectiveness}

One of the key aspects of a DSS is that the effectiveness of decision-makers can be improved. But what is really meant by a decision-maker's effectiveness? Firstly, effectiveness, as defined by Keen \& Scott Morton, is the identification of what should be done followed by ensuring the relevance of the 
chosen criterion (Keen \& Scott Morton). This should be distinguished from efficiency, which relates to the performance of a given task in as good a manner as possible in relation to certain criteria. For example, efficiency may involve minimization of time, cost, and effort required, to carry out a given activity, while effectiveness involves carrying out the right activity. Effectiveness requires a process of adaptation and learning even though the possibilities of redundancy and false starts exist.

The aim of a DSS is to improve decision-making effectiveness although it is difficult to measure this quantitatively. Efficiency can usually be measured in terms of cost and time, whereas the measurement of effectiveness requires a detailed understanding of the variables that affect performance. Therefore it cannot be proved that it is the DSS which brings about improvements in decision-making: The system may however provide the support and stimulus to the manager in achieving these improvements.

\section{The functions of a DSS}

Various characteristics of a DSS have been mentioned and described but nothing has been said about its specific functions. Blanning gives an outline of these functions, obtained from examining examples of a DSS. These functions are:

(i) Selection of data from a data base. This function is not widely used because most of these systems analyses rather than retrieve data. However, data selection may be facilitated by data base management systems and query languages.

(ii) Aggregation of data into totals, averages, frequency distributions, etc. Although this function is of limited use in solving unstructured problems, it can aid in identifying problem areas for further investigation. From the literature it is clear that aggregation is an important function of a DSS.

(iii) Estimation of the parameters in a probability distribution. This is basically statistical analysis of data, using not only statistical packages but also interactive dataanalysis packages.

(iv) Simulation to compute the anticipated consequences of proposed decisions and possible changes in the corporate environment. This has been widely used and has given rise to an abundance of computer languages for constructing and solving logistical and planning simulations. A DSS containing a corporate simulation fulfils three requirements:

- It allows a comprehensive view of the organization;

- the planning language improves the interaction between the computer and the decision-maker; and

- the construction of a simulation helps to improve the insight into interactions within the organization.

(v) Equalization to identify decisions whose consequences will meet certain consistency conditions. Typically this is accomplished by simultaneous linear equations, describing balances in the financial and material flows of a corporation, and by inter-industry economic models that balance the supply and demand in each of several industries.

(vi) Optimization to identify decisions which will maximize or minimize a single measure of performance or cost without violating constraints on other such measures (Blanning, 1979:87-97).

Although not all the functions described above may be contained in one specific DSS, generally one or more, in various combinations, will be found.

\section{The framework of a DSS}

A conceptual framework for the construction of a DSS is given here. This has been distilled from the ideas and contributions of many workers within the DSS movement.

Sprague gives a detailed description of the required framework for a DSS (Sprague, 1980a:1-26; Sprague, 1980b). Three levels of technology, i.e. hardware/software, which have been included in the label DSS are identified, namely,

(i) specific DSS,

(ii) DSS generator, and

(iii) DSS tools.

These vary in the nature and range of tasks which they can perform and in the levels of technical capability of the users.

\section{Specific DSS}

This is the system that actually accomplishes the work. It differs significantly from typical data processing applications and comprises the hardware/software that allows a decisionmaker or group of decision-makers to deal with a specific set of related problems.

\section{DSS generator}

This is a package of related hardware and software which provides a set of capabilities allowing a specific DSS to be built quickly and easily. The evolutionary process towards DSS generators has come via special-purpose languages. These include planning and modelling languages with some report generation and graphic display capabilities. The DSS generator may be described as an application development system for that class of applications called specific DSS.

\section{DSS tools}

This fundamental level of technology contains hardware and software elements which may be used for the construction and development of a specific DSS or DSS generator. DSS tools include special-purpose languages, improvements in operating systems to support conversational type models, colour graphics, etc.

The relationships between these three levels of a DSS are illustrated in Figure 1.

As can be seen from Figure 1 the DSS tools can be used to build a specific DSS directly. This is the traditional approach to developing models and systems. However, the nature of a DSS, i.e. the need to provide for constant modifications

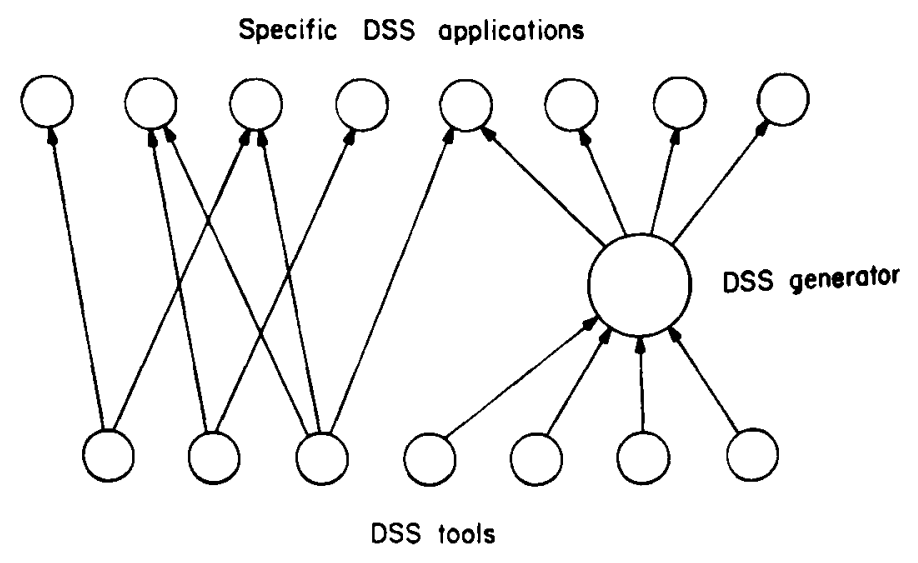

Figure 1 Three levels of a DSS. 
and flexibility, makes this approach very difficult and costly. Furthermore, as most of the changes to a DSS result from the needs of a manager or user, the DSS generator is ideal for direct user-involvement in this evolving process. The objective of a DSS generator is thus to shorten the development time for creating a specific DSS and to encourage manager/user participation in the process. For the adaptive design concept for a DSS, the role of the DSS generator is crucial. Because the system must be very flexible and adaptable to changes in the organization and its environment, the DSS cannot be developed in the traditional way appropriate to conventional modelling.

Although these three levels of technology are very useful for classification purposes they are not necessarily distinct. For example, when using APL (A Programming Language) to develop a DSS it is difficult to distinguish between these levels. One can visualize such a DSS as a continuum from the APL language itself to the functions or macros on to the actual system. The decision-maker can thus, while using the actual system, either use the APL in its basic form, or else use it to create new functions or macros, making a distinction between the various levels very fuzzy.

Three major interested parties in the development and use of a DSS are associated with these three levels of a DSS.

\section{Manager, user or decision-maker}

This is the person faced with a problem and the one directly concerned with the capability of such a system. He is the one who must take action on certain tasks and use the system to assess performance objectives in carrying out these tasks.

\section{Builder or designer}

The builder or designer is the one who uses the capabilities of the DSS generator to configure a specific DSS, as required. $\mathrm{He}$ is concerned with the way in which these capabilities may be extended.

\section{Technician or 'toolsmith'}

This group is at the DSS tool level and concerned with building the generator from the basic technological components. The technicians are also involved with basic tool development, for example, new languages, new hardware and software, etc., and the integration of these tools with the DSS generator.

\section{Development approach for a DSS}

Decision Support Systems differ in nature from traditional models and systems and therefore also require a different design approach. Keen distinguishes a DSS from other systems 'only in situations where the final system must emerge through an adaptive process of design and usage' (Keen, 1980). For the analysis and design of a DSS the traditional approaches have proved to be inadequate, basically because there is no set structure for decision-making and because of the continually changing conditions that decision-makers face.

A DSS should be built in such a way as to facilitate rapid feedback from the user to ensure it is proceeding correctly and to permit changes quickly and easily. Keen (1980) gives four reasons for this need:

(i) The designer or user may not be able to provide functional specifications or may be unwilling to do so.

(ii) Users may not know precisely what they want and designers may not understand what users need and can accept.

(iii) Users' concepts of the task or decision situation will be shaped by the system.

(iv) Intended users of the system require sufficient autonomy to handle the task in a variety of ways or to differ in their approach to such an extent that standardization is prevented. In this situation any computer support must allow personalized usage and must be flexible.

Development of a DSS can be characterized by two stages.

\section{Iterative stage}

This stage is highlighted by the fact that the four most important steps in the system-development process - analysis, design, construction, and implementation - are combined into one step and are repeated iteratively. This iterative approach basically means that an initial system, however small, is designed and developed to support the decision-making aspects that are immediately relevant. This system is then evaluated, modified and expanded a number of times, until a relatively stable system, supporting a wide range of tasks, is obtained. Very close involvement or participation of management is usually required at this level.

\section{Adaptive development}

In very broad terms a DSS consists of all three levels of technology, i.e., specific DSS, DSS generator, and DSS tools, all which adapt and change over time. This Keen (1980) calls the 'middle-out design' strategy. It implies that defining a system as a DSS rather than as an interactive information retrieval system does make a difference. It shifts the focus of the development process from delaying implementation until a 'final' system has been clearly defined, to starting as quickly as possible and implementing an initial system, which can then be modified and adapted through an evolving process.

\section{Components of a DSS}

Sprague (1980a; 1980b) identifies three components of a typical DSS, namely, a data base, a model base, and a complex software system for linking the user to each of the two other components. The data base and model base have some interrelated components while the software system typically also has three components, i.e., a data base management system, a model base management system, and the software to manage the interface between the user and the system.

Some aspects and capabilities required in each of the components are now discussed.

\section{Data-base subsystem}

The data-base subsystem provides the data requirements of a DSS and is, because of recent advances in data bases and data base management technology, well-understood and applied in the DSS environment. The data set contains inter alia data from internal and external sources, accounting oriented transactional data, nontransactional data and nonaccounting data.

Ideally the data-base subsystem should be able:

(i) To combine a variety of data sources through a data capture and extraction process;

(ii) to add and delete data sources quickly and easily;

(iii) to portray logical data structures in user terms so that the user understands what is available and can specify needed additions and deletions;

(iv) to handle personal and unofficial data so that the user can experiment with alternatives based on personal judgement; 
(v) to manage this wide variety of data with a full range of management functions.

\section{Model-base subsystem}

This subsystem contains the modelling or analytical component of a DSS. The models are embedded in the information system with the data base as the integration and communication mechanism between them.

The key capabilities for a DSS in the model subsystems are, amongst others:

(i) To create new models easily and quickly;

(ii) to comprise a wide range of models supporting all levels of decision-making;

(iii) to interrelate models with appropriate linkages through the data base;

(iv) to access and integrate the various model-building 'blocks';

(v) to manage the model base with management functions analogous to data-base management ie., cataloguing and linking.

\section{User-system interface}

Most of the success of a DSS depends on the flexibility and usability of the user-system interface because it is through this that the user communicates with the system. To the user this is the system.

The interface consists of three parts:

(i) The action language - what the user can do in communication with the system;

(ii) the display language - what the user sees;

(iii) the knowledge base - what the user must know in order to use the system effectively (Bennett, 1977:3-11).

Some of the desirable capabilities of the user-system interface are to be able to:

(i) Handle a variety of dialogue styles;

(ii) accommodate user actions in a variety of media;

(iii) present data in a variety of formats and media;

(iv) provide flexible support for the user's knowledge base.

\section{Performance requirements of a DSS}

Sprague (1980a) gives a list of six requirements of a DSS from the point of view of the manager/user. It is obvious that not all these requirements need necessarily be satisfied in a single DSS; this will depend on the type of system and on the task it supports. The requirements are the following:

(i) A DSS should provide support for decision-making but with the emphasis on semi-structured and unstructured decisions. Managers need additional support for certain kinds of problems.

(ii) A DSS should provide decision-making support for managers at all levels, assisting in integration between the levels whenever appropriate.

(iii) A DSS should support decisions which are interdependent, as well as those that are independent. Keen \& Hackathorn (1979) argue that there should be a distinction between three decision types:

- Independent. In this case a decision-maker has full responsibility and authority to make a decision. There are thus no interdependencies involved. They suggest such a system should be called a Personal Support System (PSS).

- Pooled interdependent. Here there are 'pooled' interdependencies and it requires substantial face-to-face discussion and negotiation between the decision- makers before a decision is reached. Group Support System (GSS).

- Sequential interdependent. A part of the decision is made by one decision-maker who then passes it on to the next. Organizational Support System (OSS). For example, a PSS may support a manager's own budget decision, a GSS the budget negotiation, and an OSS the organizational budget process.

(iv) A DSS should support all phases of the decision-making process. Within this context it is useful to recall the popular model of the decision-making process as given by Simon (1960). Three main steps or phases are characterized:

- Intelligence. One looks for conditions in the environment calling for decisions and collects the appropriate raw data. These data are processed and examined for clues that may identify problems.

- Design. Various alternative sources of action are invented, developed and analysed. This involves understanding the problem, generating solutions and testing solutions for feasibility.

- Choice. In this phase a particular alternative is selected and implemented.

(v) A DSS should support a variety of decision-making processes but should not be dependent on any one.

(vi) A DSS should be easy to use, i.e., it should be flexible, user-friendly, non-threatening, etc.

\section{Justifying DSS}

Keen (1981:1-15) addresses the problem of justifying or assessing proposals for developing a DSS. The benefits, as cited by users of such systems, include the ability to examine more alternatives; obtaining a better understanding of the business or company; fast response to unexpected situations; the ability to carry out ad hoc analysis; new insights and learning; improved communication and control; cost savings; better decisions; more effective team work; time saving and better use of data resources. Most of these benefits are qualitative and therefore traditional cost-benefit analysis is not well-suited. Because of the changing and adaptive nature of a DSS as it responds to a user's experience and learning, it is very difficult to identify the costs of such a system. It thus seems that the decision to build a DSS is based on the value and usefulness rather than on costs.

Keen (1981) suggests that a value-analysis approach be followed. This is a systematic methodology that focuses on:

(i) Value first, cost second;

(ii) simplicity and robustness;

(iii) reducing uncertainty and risk; and

(iv) innovation, rather than routinization.

The value analysis involves a two-stage process:

(i) Firstly, an initial small-scale system, called version 0, is built. This system is complete in itself and the decision to build it is based on:

(a) An assessment of the benefits which are necessarily quantifiable; and

(b) a cost threshold whereby one determines whether it is worth investing this amount of money to get these benefits.

(ii) In subsequent stages, more comprehensive systems will be developed, each new development following an assessment of the success of the existing version. The decision to develop the extended system is based on:

(a) A cost analysis of this larger system; 
(b) a value threshold which means that one would try to determine what level of benefits is needed to justify the cost and also what the likelihood is that these levels will be attained, based on experience in using the current system.

The major advantage of this approach is a reduction of the risks involved in the development of Decision Support Systems. It also simplifies the balance between costs and benefits. This is a more natural approach than the traditional cost benefit analysis: Until value is established any cost is disproportionate.

\section{DSS applications}

The number of DSS applications is increasing rapidly. Alter (1980) reports on 56 applications of which the following are examples:

(i) A portfolio management system for a large bank with portfolio investment management and capital investment applications;

(ii) a corporate planning system for a shipping corporation with operational planning, transportation analysis, and capital expenditure applications;

(iii) an analytical management system for an airline company supporting planning operations, operations for financing and marketing; and

(iv) a computer assisted under-writing system which was developed to assist investment underwriters in calculating and tracking group-insurance policies and renewals.

One DSS which has been used very successfully for different problem areas is an interactive system called Geodata Analysis and Display System (GADS) developed in the early 1970's (Sprague \& Carlson, 1982). This system was initially used by police officers in designing more efficient allocations of personnel on the beats. Later it was also used for burglary analysis and for analysing calls for service. By loading different maps, data files, etc., into the basic system, it was possible to develop various specific DSS's in areas such as urban planning (for growth policy evaluation and growth evaluation), fire departments (for inspection and fire equipment planning), human service delivery evaluation, commuter bus route planning, shopping centre location and customer engineer territory planning.

Other applications include:

(i) MOPASS (Marine Operations Planning and Scheduling System), a model-based DSS for planning and scheduling ocean-borne transportation. This system's applications range from long-term management planning to day-to-day operations scheduling, as well as hour-to-hour assessment of financial opportunities (Scott \& Douglas, 1981:1-10).

(ii) PBDS (Programmed Blood Distribution System), a DSS for regional blood management, this system, through centralized management and prescheduled deliveries via a distribution system, has as prime objective the optimization of the allocation of regional blood resources. This is achieved by using both optimization and subjective management in comparing conflicting performance objectives (Prastacos \& Brodheim, 1980:451-463).

(iii) A DSS for location and allocation problems within a brewery. More specifically, this system was developed for supporting strategical and tactical decision-making with respect to the location of warehouses and the allocation of customers to warehouses (Van Numen \& Benders, 1980:96-105).
The benefits of DSS applications vary as can be expected given the complex nature of the tasks they support and their personalized use. Some of the benefits that have been cited in DSS applications are: An increase in the number of alternatives examined; better understanding of the business; new insights and learning; fast response to unexpected situations; cost savings, better solutions; etc.

\section{Conclusion}

The key question for anyone working on a DSS is: What specific decision or decision process am I trying to support? It is important to realize that many managerial problems are non-trivial and cannot be fully automated. One should therefore start from the decision-maker's activities and shape the system to suit his problems and needs. As was indicated previously, a DSS supports rather than replaces the decisionmaker. The complete system comprises both the decisionmaker and the machine (computer). It should be seen more as a service than as a 'final' product. Another characteristic is that a DSS constantly grows and evolves as its user adapts and learns, and as the demands of the situation and the environment change.

The DSS approach is concerned with the use of computers in aiding decision-making. It has grown rapidly in the last few years, together with technological advances, at a time when researchers in many different fields have begun to focus on the problem of implementation. The list of background disciplines that have an impact on DSS includes computer science (data base and language theory), operations research (simulation and especially multiple criteria decisionmaking), cognitive psychology (user interfaces and decisionmaking styles) and artificial intelligence (knowledge data base and expert systems). It thus offers opportunities for all of these fields to meet on common ground.

From this survey it should be clear that DSS is not merely another 'buzz word' but that there is significant content to this label. It also shows that if used correctly and in the defined way, the DSS fulfils the function of a decision-making support system that, in the words of Ackoff (1979b), can 'learn and adapt quickly and effectively in rapidly changing situations'.

\section{References}

Ackoff, R.L. 1979a. The future of operational research is past. J. Oper. Res. Soc., vol.30, 93-104.

Ackoff, R.L. 1979b. Resurrecting the future of operational research. J. Oper. Res. Soc., vol.30, $189-199$.

Alter, S.L. 1980. Decision Support Systems: Current Proctice and Continuing Challenges. Reading, Massachusetts: Addison Wesley.

Bennett, J. 1977. User-oriented graphics, systems for decision support in unstructured tasks. In User-Oriented Design of Interactive Graphics Systems, (Ed.) S. Treu. New York: Association for Computing Machinery, 3-11.

Blanning, R.W. 1979. The functions of a Decision Support System. Inf. Manage., vol.2, $87-97$

Bonczek, R.H., Holsapple, C.W. \& Whinston, A.B. 1981. Foundations of Decision Support Systems. New York: Academic Press.

Carlson, E.D. 1977. (Ed.) Proceedings of a Conference on DSS. Data base, vol.8(3).

Keen, P.G.W. 1980. Decision Support Systems: A Research Perspective. In Decision Support Systems: Issues and Challenges. Proceedings of an International Task Force Meeting, 11ASA Proceedings Series. Pergamon Press.

Keen, P.G.W. 1981. Value analysis: justifying Decision Support Systems, MIS $Q$., vol.5, (1), 1-15.

Keen, P.G.W. \& Hackathorn, R.D. 1979. DSS and Personal Computing. Philadelphia, Pennsylvania: Department of Decision Sciences, 
The Wharkas Schood, The University of Pennsytvania, Working Paper 79-01-03.

Cen, PG.W. \& Scot Monon, M.S. 1978. Decision Support Systems: An Organizotional Perspective. Reading, Massachuscts: Addison-Wexicy.

ieen, PG.W. Wagner, G.R. 1979. DSS: An erocutive mind-support system, Dutamation, 117-122.

kylor, T.H. 1982. Decision Support Systems or whatever happened to MIS? Inierfoces, vol.12, (4), 92-94.

rasucos, G.P. \& Brodheim, E. 1980. PBDS: A Decision Support System for regional blood management. Manoge. SCi, vol.26, (5), 451- 463.

icon, K.L. \& Douglas, BW. 1981. A modedbased Decision Support System for planning and scheduling ocean-borne transportation. Interfoces, vol.II, (4), 1-10.

icott Morton, MS. 1977. Management Decision Systems Computer based suppoon for decision making Cambridge, Massachusetts:
Division of Research, Harvard University.

Simon. H. 1960. The New Science of Management Decision. New York: Harper \& Row.

Sprague, R.H. 1980a. A framework for the development of Decision Suppon Systems, MIS $Q$, vol.4, (4), 1-26.

Sprague, R.H. 19806. A framework for research on DSS. In DSS. Issues and Challenges. Proceedings of an International Task Force Meeting.

Sprague, R.H. \& Carlson, E.D. 1982. Building Effective Decision Sup port Systems. Englewood Cliffs, New Jersey: Prentice Hall.

Van Numen, J. \& Benders, J. 1980. A Decision Support System for location and allocation problems within a brewery. O.R. Proceedings 1980. Berlin, Heidelberg: Springer Verlag, 96-105.

Vazsonyi, A. 1978. Decision Support Systems: The new technology of decision making? Interfaces, vol.9, (1), $72-^{-} 7$.

Wagnet, G.R. 1981. Decision Support Systems: The real substance Interfaces, vol.11, (2), 77-86. 